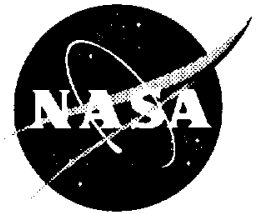

\title{
A Thin Film Multifunction Sensor for Harsh Environments
}

John D. Wrbanek, Gustave C. Fralick, and Lisa C. Martin

Glenn Research Center, Cleveland, Ohio

Charles A. Blaha

Akima Corporation, Cleveland, Ohio

Prepared for the

37th Joint Propulsion Conference and Exhibit

cosponsored by the AIAA, ASME, SAE, and ASEE

Salt Lake City, Utah, July 8-11, 2001

National Aeronautics and

Space Administration

Glenn Research Center

July 2001 


\section{Acknowledgments}

The authors would like to thank Dr. Jih-Fen Lei, now Chief of the Instrumentation and Controls Division at NASA

Glenn Research Center, and Dr. Herbert Will, now retired from the Instrumentation and Controls Division, for their work on the original design of the multifunction sensor. Also, they would like to thank

Dr. Valarie Thomas of the Ohio Aerospace Institute for her help in reviewing this work.

This report is a formal draft or working paper, intended to solicit comments and ideas from a technical peer group.

This report is a preprint of a paper intended for presentation at a conference. Because of changes that may be made before formal publication, this preprint is made available with the understanding that it will not be cited or reproduced without the permission of the author.

Available from

NASA Center for Aerospace Information 7121 Standard Drive

Hanover, MD 21076
National Technical Information Service 5285 Port Royal Road Springfield, VA 22100 


\title{
A THIN FILM MULTIFUNCTION SENSOR FOR HARSH ENVIRONMENTS
}

\author{
John D. Wrbanek, Gustave C. Fralick, and Lisa C. Martin \\ National Aeronautics and Space Administration \\ Glenn Research Center \\ Cleveland, Ohio 44135 \\ Charles A. Blaha \\ Akima Corporation \\ Brook Park, Ohio 44142
}

\begin{abstract}
The status of work at NASA Glenn Research Center to develop a minimally intrusive integrated sensor to provide real-time measurement of strain. heat flux and flow in high temperature environments is presented in this paper. The sensor can be beneficial as a single package to characterize multiple stress and strain modes simultaneously on materials and components during engine development and validation. A major technical challenge is to take existing individual gauge designs and modify them into one integrated thin film sensor. Ultimately, the goal is to develop the ability to deposit the sensors directly onto internal engine parts or on a small thin substrate that can be attached to engine components. Several prototype sensors constructed of platinum, platinum-rhodium alloy, and alumina on constant-strain alumina beams have been built and bench-tested. The technical challenges of the design, construction, and testing are discussed. Data from the preliminary testing of the sensor array is presented. The future direction for the sensor development is discussed as well.
\end{abstract}

\section{GOALS}

To meet the needs of aeronautic and aerospace research for measurement of high stress and heat loading on critical system components, NASA Glenn Research Center has been pursuing thin film physical sensor development. These thin film sensors are micro-scale in construction, and designed to be capable of measurements in the high temperature environments that engine components are exposed to. For example, these sensors are designed to withstand the presence of high temperature, high pressure, large stress/strain, large vibration as well as the severe thermal transient due to the cryogenic to combustion temperature change that occurs in high-pressure propulsion. Developed over a number of years, components of this technology have been demonstrated up to $1100^{\circ} \mathrm{C}$ in a variety of engine conditions. ${ }^{1.2}$ However, each sensor only provides information on one parameter at a time. In order to provide as much detailed information as possible from a single sensor unit, a multifunction sensor array approach has been pursued.

This work further develops the various microfabricated thin film sensors needed for the next generation of engines and integrates them into a single array for real-time measurement of strain, heat flux, temperature, and flow. The complete physical sensor array produced in this work is designed such that multiple physical parameters (temperature, strain, vibration, or heat flux) can be obtained simultaneously from a single unit. The sensing elements are initially fabricated of high temperature materials such as platinum $(\mathrm{Pt})$ and platinumrhodium (PtRh) alloys. This sensor technology can be applied to characterize propulsion components during their design and characterization development phase as well as during the operational phase.

The technology has applications to RocketBased Combined Cycle (RBCC) and Turbine-Based Combined Cycle (TBCC) systems as well as to future launch vehicles, space vehicles, and ground systems. The resulting data can be used to verify the cooling system integrity including surface temperature, heat flux, and deformation. The increased understanding of the thermal and aerodynamic loads on system components will lead to an increased understanding of operating conditions and capabilities. Simultaneous measurement of temperature, strain, heat flux. and vibration will greatly aid in validating design codes. This will have a direct positive impact on improving system safety and reducing system design and development cost through a more thorough understanding of system operating conditions and capabilities. This capability is fundamental since there are engine environments in which optical access is not possible. 
These MicroElectroMechanical Systems (MEMS) based thin film sensors are being fabricated in a class 1000 clean room at NASA Glenn Research Center using physical vapor deposition and photolithography technologies. Surface analytical tools will be used to characterize these thin film sensors. The sensor response to strain, heat flux, temperature, and flow will be characterized as well.

\section{DESIGN}

To meet the challenge of designing a single package sensor that combines the capabilities of several different sensors, and still be minimally intrusive in a hostile engine environment, the development of a MEMS-based sensor using high temperature metals is pursued. The sensor is conceptualized as having two major sub-gauges: 1) the strain and flow gauge, and 2) the heat flux and temperature gauge.

For the strain magnitude and direction, as well as for the flow magnitude and direction, a microfabricated triangular strain gauge design is used. The patented design, developed at NASA Glenn Research Center, ${ }^{3}$ modified a rosette pattern strain gauge by linking the three legs of the rosette together and powering them under a single constant current source. A schematic of the concept for the triangular gauge is shown in Figure 1.

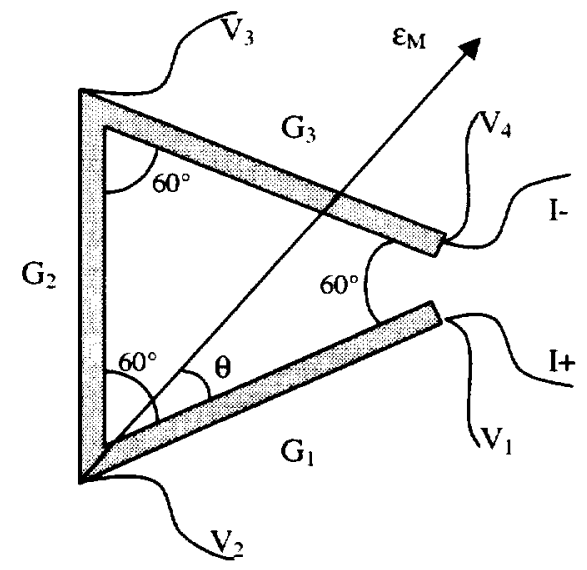

Figure 1: Concept for the Microfabricated

Triangular Strain Gauge.

The strain $\left(\varepsilon_{M}\right)$ applied to the triangular gauge is sensed as individual strains by each of the three legs $\left(\varepsilon_{G 1}, \varepsilon_{G 2}, \varepsilon_{G 3}\right)$ of the rosette. These strains are determined by measuring the increase or decrease of the voltage drop along each leg due to the strain from the voltage drop measured with no strain (i.e., $\Delta V_{G 1}=V_{12}($ strain $)-V_{12}($ no strain $), \Delta V_{G 2}=$
$V_{23}($ strain $)-V_{23}($ no strain $), \Delta V_{G 3}=V_{34}($ strain $)$ $V_{34}($ no strain) ). The measured fractional change in the voltage drop is proportional to the strain seen on the leg by a gauge factor $(G f)$ :

$$
\begin{aligned}
& \varepsilon_{G 1}=\frac{\Delta V_{G 1}}{V_{12} * G f} \\
& \varepsilon_{G 2}=\frac{\Delta V_{G 2}}{V_{23} * G f} \\
& \varepsilon_{G 3}=\frac{\Delta V_{G 3}}{V_{34} * G f}
\end{aligned}
$$

The rosette geometry provides the ability to measure the strain angle and magnitude from these measurements:

$$
\begin{aligned}
& \theta=\frac{1}{2} \tan ^{-1}\left(\frac{\sqrt{3}\left(\varepsilon_{G 2}-\varepsilon_{G 3}\right)}{2 \varepsilon_{G 1}-\varepsilon_{G 2}-\varepsilon_{G 3}}\right) \\
& \varepsilon_{M}=\frac{2}{3}\left(\frac{2 \varepsilon_{G 1}-\varepsilon_{G 2}-\varepsilon_{G 3}}{\cos 2 \theta}\right)
\end{aligned}
$$

From the apparent strain $\left(\varepsilon_{a p p}\right)$ and the temperature coefficient of resistance $(\alpha)$ for the material used to make the rosette, the temperature change $(\Delta T)$ of the sensor can be found as well:

$$
\begin{aligned}
& \varepsilon_{a p p}=\frac{\varepsilon_{G 1}+\varepsilon_{G 2}+\varepsilon_{G 3}}{3}-\frac{\varepsilon_{M}}{2} \\
& \Delta T=\frac{\varepsilon_{a p p} * G f}{\alpha}
\end{aligned}
$$

These equations for rosette gauges is utilized to give strain magnitude and direction, but with half of the lead wires required for a standard rosette gauge. Also. by measuring the resistance change in the gauge under high current conditions, the sensor can be calibrated for flow measurement as an anemometer.

A palladium-13\%chromium alloy ( $\mathrm{Pd} 13 \mathrm{Cr})$ was originally chosen as a strain gauge material due to the extensive work with this alloy that was pursued at NASA Glenn Research Center. ${ }^{47}$ However, this alloy is limited to temperatures under $1100^{\circ} \mathrm{C}$ for strain applications. ${ }^{8}$ To meet the goal for the sensor to exceed $1000^{\circ} \mathrm{C}$, the strain gauge metal was changed to platinum, which is not as susceptible to oxidation and physical changes at high temperatures. 
The determination of heat flux and temperature is accomplished by utilizing a microfabricated thin film heat flux gauge developed at NASA Glenn Research Center. ${ }^{1.9}$ The thin film heat flux gauge is a thermopile type, circular with two thickness of ceramic insulator, as shown in Figure 2.

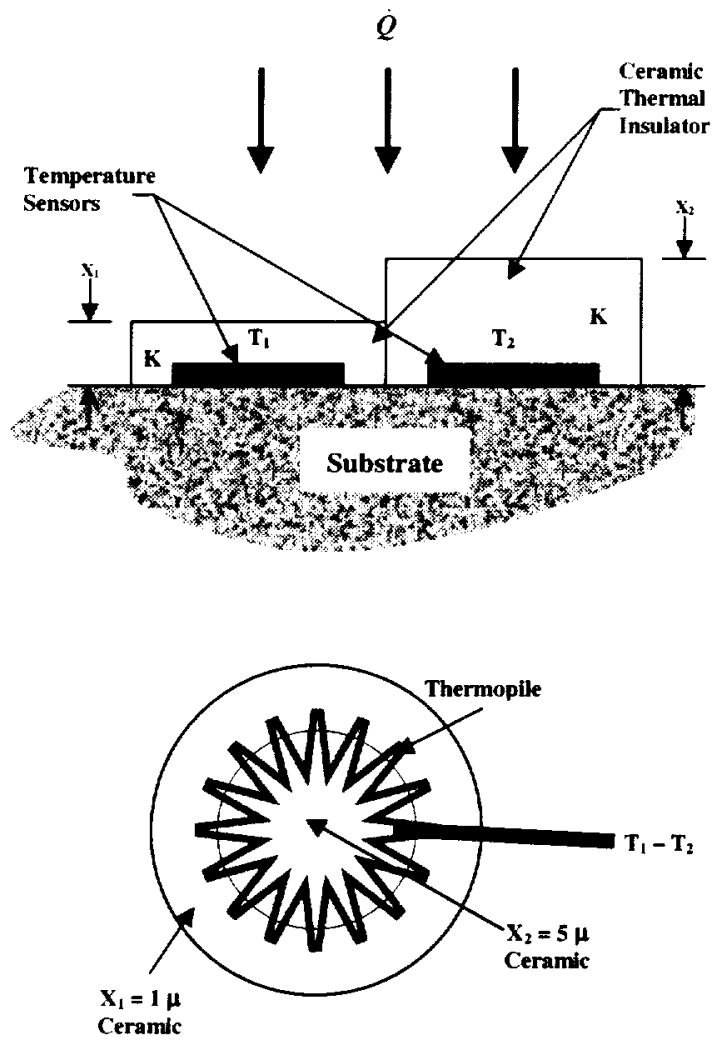

Figure 2: Concept for the Microfabricated Thin Film Heat Flux Gauge used on the Multifunction Sensor.

The heat flux $\left(Q^{*}\right)$ is determined by measuring the temperature variation $\left(T_{1}-T_{2}\right)$ under two thicknesses of insulator $\left(x_{2}-x_{l}\right)$ by the equation:

$$
\dot{Q}=K \frac{\left(T_{1}-T_{2}\right)}{\left(x_{2}-x_{1}\right)}
$$

where $K$ is the thermal conductivity. Assuming the thermopile is small enough such that the flux is uniform over its width, the voltage output is proportional to the heat flux passing into the gauge.

Since the gauge is to be operated in a high temperature harsh environment, the thermopile consists of pairs of Type R platinum-13\%rhodium vs. platinum (Pt13Rh/Pt) thermocouples. To amplify the small signal from this thermocouple type. 40 pairs of thermocouples are used. A thermocouple on the gauge provides the surface temperature of the system.

The resulting design in integrating the two gauges is shown in Figure 3. The triangular strain gauge wraps around the heat flux gauge which is made up of $\mathrm{Pt13Rh} / \mathrm{Pt}$ thermocouples. The entire gauge is enclosed in a triangle approximately $1.5 \mathrm{~cm}$ on a side and having element line widths of $50 \mu \mathrm{m}$.

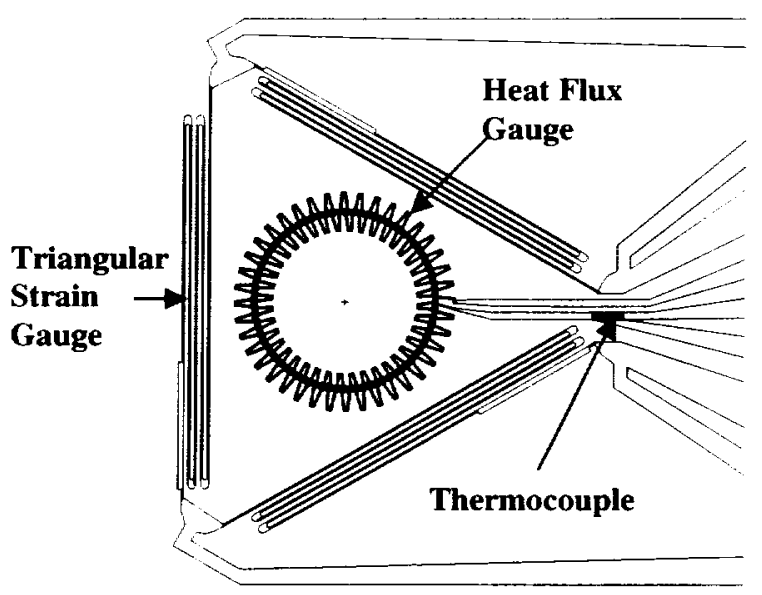

Figure 3: Design of the Multifunction Sensor.

\section{FABRICATION}

The sensors for this work were fabricated in the Microsystems Fabrication Lab, a class 1000 clean room facility in the Instrument Research Laboratory at NASA Glenn Research Center. To date, three sensors for this effort have been produced, as shown in Figures $4 \& 5$. The first sensor was a proof-ofconcept triangular strain gauge designed to demonstrate the validity of the modifications to the rosette pattern in thin films. This was produced by sputter depositing 5 microns of platinum on a constant-strain alumina beam patterned by using a metal shadow mask to make the 100 -micron wide elements for the gauge. Since the only purpose of this sensor was to demonstrate the validity of the strain gauge concept, the heat flux gauge was not integrated.

The second and third sensors were prototype designs on constant-strain alumina beams. They incorporated the strain gauge and heat flux gauge patterns on one sensor. Since the strain gauge material was identical to the material used as the 
negative side of the thermopile, a two metal process was developed for depositing the thin film sensor.

The first prototype sensor was deposited with 1 micron of platinum and the second with 1.2 microns of platinum. The sensors were patterned by using a lift-off process involving a copper sacrificial layer to attain precise line widths in platinum. ${ }^{10}$ A diagram of the procedure is shown in Figure 6.
The first prototype sensor did not have the Pt13Rh patterned, and was used to demonstrate the triangular strain gauge as designed to be incorporated into the multifunction gauge. The second prototype was deposited with 1 micron of Pt13Rh to complete the heat flux sensor. The second prototype was then coated with 0.3 micron of alumina, with another 5 microns deposited on the center of the heat flux gauge.

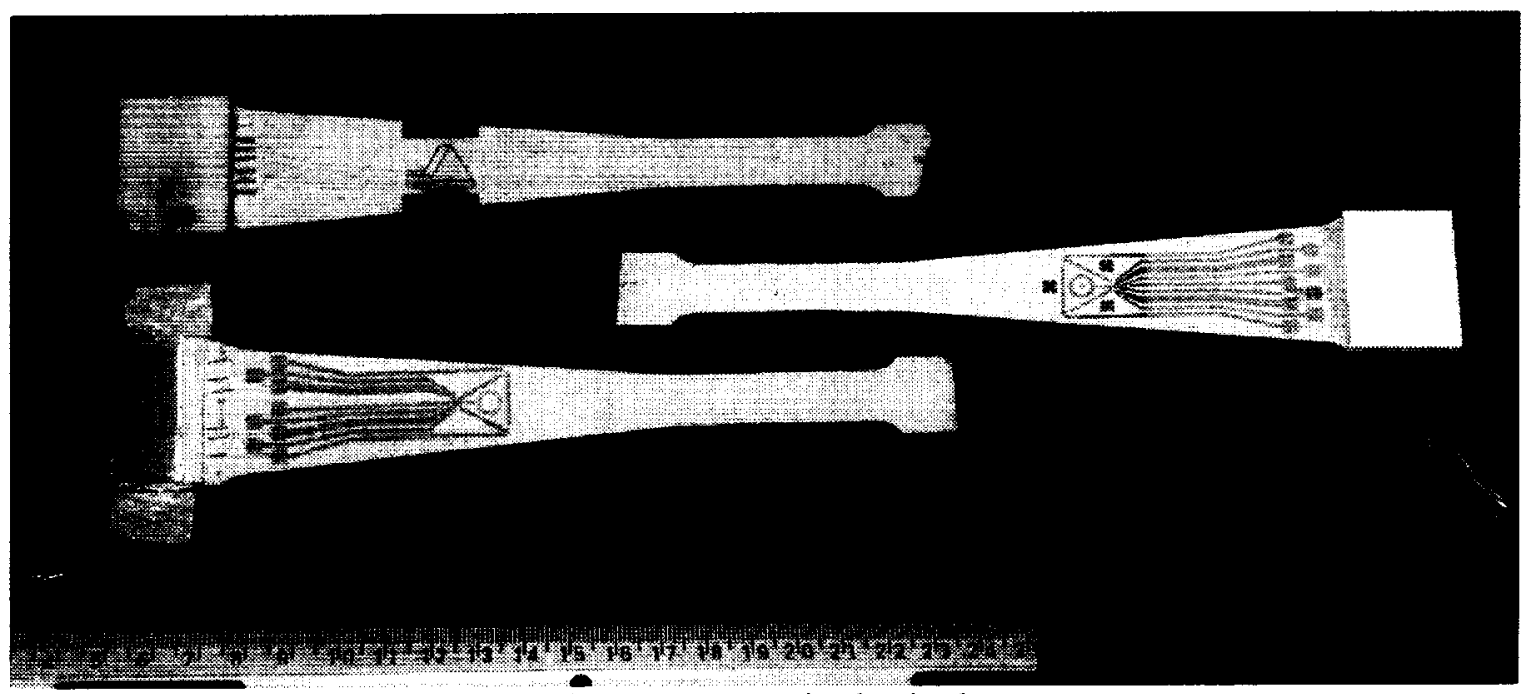

Figure 4: The three sensors bench-tested on constant-strain alumina beams

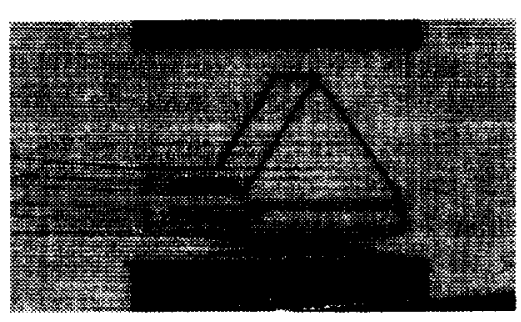

(a)

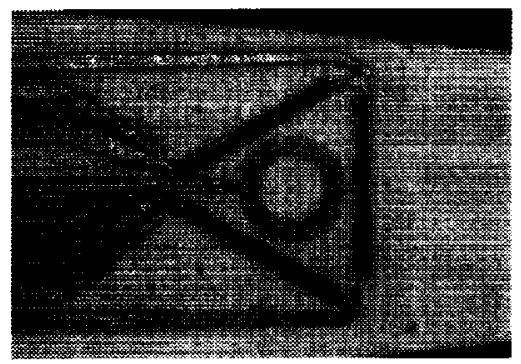

(b)

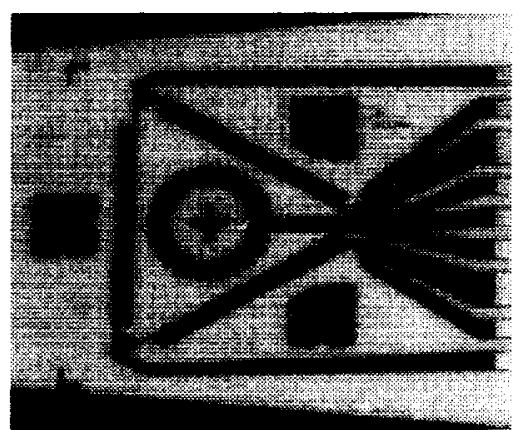

(c)

Figure 5: Close-up of the three sensors bench-tested: a) The proof-of-concept sensor; b) the first prototype sensor; and c) the second prototype sensor. 

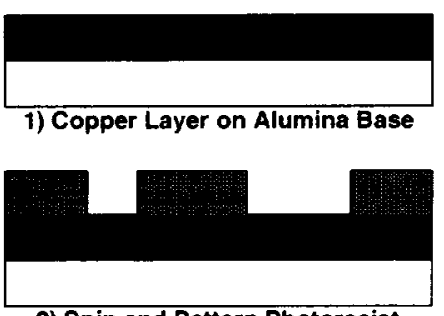

2) Spin and Pattern Photoresist

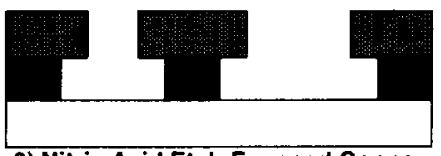

3) Nitric Acid Etch Exposed Copper

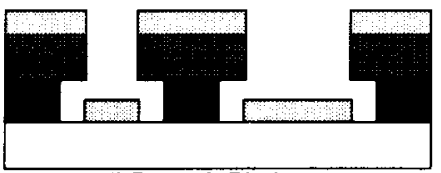

4) Deposit Platinum

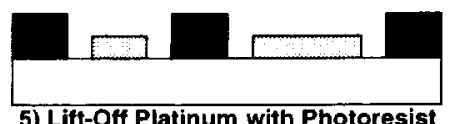

5) Lift-Off Platinum with Photoresist
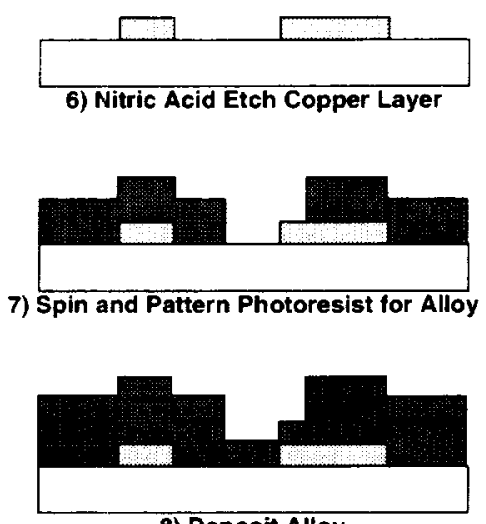

8) Deposit Alloy
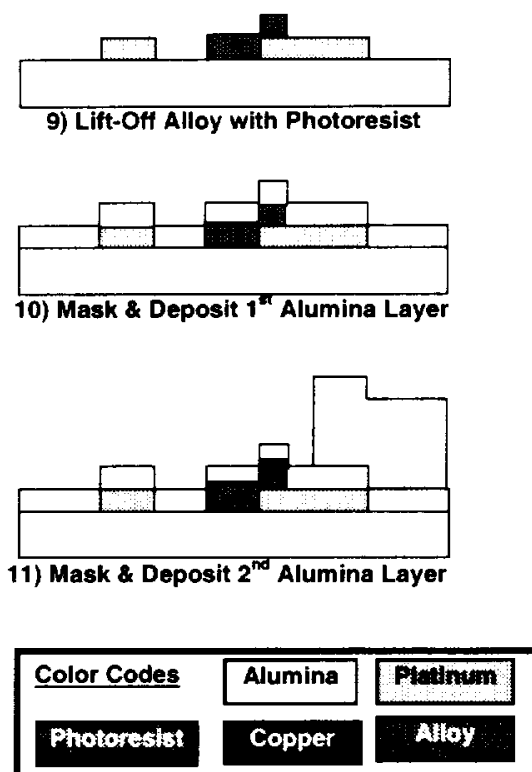

Figure 6: Lift-off Process used in constructing the Multifunction Sensor (Patent Pending to Akima Corp.)

\section{TESTING}

The three sensors were tested for response to strain. flow and heat at the Instrument Research Laboratory at NASA Glenn Research Center to validate the multifunction gauge design before testing in an engine-type environment. The proof-of-concept sensor was tested for strain response, the first prototype sensor was tested for strain and flow response, and the second prototype sensor was tested for strain and heat response. The environment was limited to ambient bench-top conditions in these tests.

\section{Strain}

The sensors were tested for strain response on a Dynamic Load Test Rig. as shown in Figure 7. A constant current source supplied the excitation current to the sensors, and the signals were filtered and then amplified before being collected by a computer. The maximum strain on the sensors was measured to be 230 microstrain $(\mu \varepsilon)$ based on displacement measurements on a beam in the rig and measurements using a commercial strain gauge mounted on a similar constant-strain alumina beam. Measurements of both the static and dynamic response of the sensors were made and the results are shown in table 1. The dynamic measurements were made with the motor rotating at $5 \mathrm{~Hz}, 10 \mathrm{~Hz}$, and $15 \mathrm{~Hz}$. The responses of the strains were found to be consistent for each individual sensor with a variance of $\pm 10 \%$. The results of the tests are shown in Table 1 .

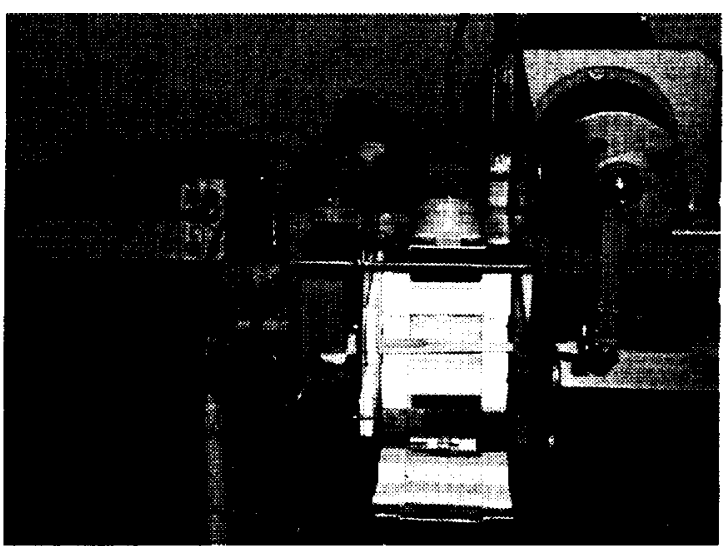

Figure 7: Dynamic Loading Test Rig

Table 1: Results of Strain Bench-Testing

\begin{tabular}{|l|c|c|c|c|c|c|}
\hline \multicolumn{1}{|c|}{ Sensor } & Mode & Current & $\begin{array}{c}\Delta R \\
\text { max. }\end{array}$ & Total R & $\begin{array}{c}\text { Gauge } \\
\text { Factor }\end{array}$ & $\begin{array}{c}\text { Strain } \\
\text { Angle }\end{array}$ \\
\hline $\begin{array}{l}\text { Proof-of- } \\
\text { Concept }\end{array}$ & Dynamic & $109 \mathrm{~mA}$ & $1.21 \mathrm{~m} \Omega$ & $3.63 \Omega$ & 4.4 & $-1^{\circ}$ \\
\hline $\begin{array}{l}\text { First } \\
\text { Prototype }\end{array}$ & Static & $7.2 \mathrm{~mA}$ & $255 \mathrm{~m} \Omega$ & $1200 \Omega$ & 2.8 & $-30^{\circ}$ \\
\cline { 2 - 7 } & Dynamic & $7.2 \mathrm{~mA}$ & $284 \mathrm{~m} \Omega$ & $1200 \Omega$ & 3.1 & $-29^{\circ}$ \\
\hline $\begin{array}{l}\text { Second } \\
\text { Prototype }\end{array}$ & Static & $6.0 \mathrm{~mA}$ & $132 \mathrm{~m} \Omega$ & $480 \Omega$ & 3.6 & $-32^{\circ}$ \\
\cline { 2 - 7 } & Dynamic & $6.0 \mathrm{~mA}$ & $136 \mathrm{~m} \Omega$ & $480 \Omega$ & 3.7 & $-32^{\circ}$ \\
\hline
\end{tabular}


Considering that the gauge factor for platinum wire of the size of our traces is $4.00,{ }^{11}$ the sensors responded well to our bench testing. The proof-of-concept gauge gave a gauge factor close to this wire value. The gauge factor of the first prototype sensor was between 2.8-3.1, considerably lower than the expected value. The $1200 \Omega$ resistance also was considerably different than the $360 \Omega$ expected, which may suggest impurities in the material for that sensor. The second prototype sensor's $480 \Omega$ resistance was as expected, and the gauge factor of between 3.6-3.7 was very close to the wire value. These deviations of the gauge factor may be explained by noting that our film is fixed to the surface of the testing beam along its entire length, unlike a wire, which will effect the deformation of the film when under strain.

The angle determined from the three-leg rosette strain gauge algorithm was also reasonable. The proof-of-concept sensor was oriented to give a strain angle of $0^{\circ}$, and the first and second prototype sensors were oriented at $-30^{\circ}$. From these results, the orientation is accurate to $\pm 1^{\circ}$, and the measurements are accurate to $\pm 1^{\circ}$. For these bench tests, a total accuracy better than $\pm 3^{\circ}$ is acceptable.

\section{Flow}

The flow response was investigated using the first prototype sensor and a cool air gun. The response to changes in the voltage across one leg was observed while air was blown transversely and longitudinally across the leg. Currents between 10 milliamps and 50 milliamps were used. The results are plotted in Figure 8.



Figure 8: Response of one leg of the first prototype sensor to airflow
The response to longitudinal airflow was linear with the current, with the transverse flow response weaker for currents exceeding 20 milliamps. From the trends shown in Figure 8, it is estimated that a 170 milliamp (35 Watt) current source would be needed to achieve longitudinal responses 5 times as great as the transverse response. Though this indicates that the multifunction gauge could be used to determine airflow, the exact incorporation using this high current with a low excitation current strain gauge remains unclear, as well as the resolution of transverse and longitudinal flows.

\section{Heat}

The second prototype sensor had a heat flux gauge integrated with a triangular strain gauge. The sensor on the alumina substrate was clamped to a metal shim, and then exposed to a heat gun blowing perpendicular to the surface. The resulting signal is shown in Figure 9. Though the signal was not amplified or filtered, it was consistent with heat flux responses seen in gauges of the same design.' The signal reached a level shortly after the heat was applied. When the heat gun is turned off, the heat flux became negative as the sensor is cooled from the ambient air currents above the sensor.

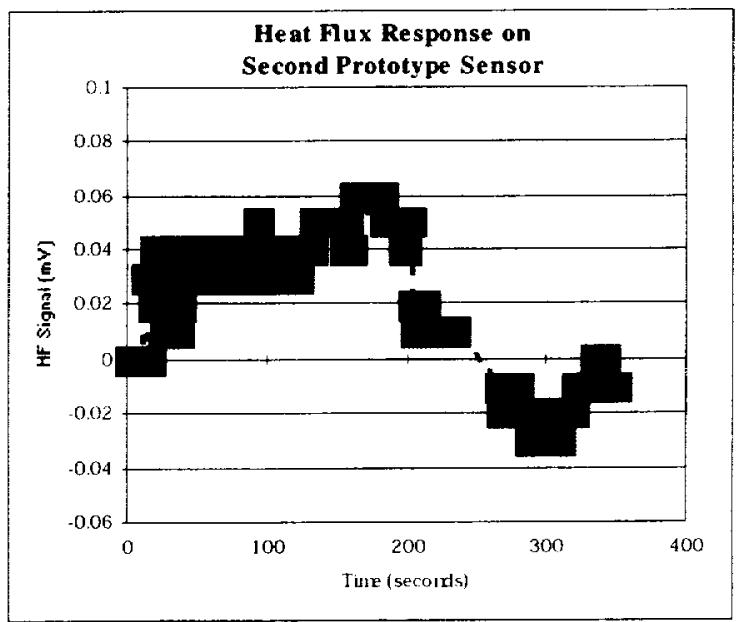

Figure 9: Heat flux response on the second prototype sensor.

\section{FUTURE TESTING AND CONCLUSIONS}

The design of the multifunction sensor has been bench-tested on three test sensors. The next level of testing involves the fabrication and testing of the sensor on an engine component. The first 
component that has been chosen for testing is a silicon carbide ceramic matrix composite watercooled thruster housing.

By testing the sensor in an engine environment, the architecture and material limits can be better understood in developing an improved sensor design. Further tests will need to be accomplished to verify the design in harsher environments in order to push these limits. As these limits are met, alternate materials will be explored for the sensor. Ceramic thermocouple and strain gauge materials show promise and may be used as an alternate to the metals in the sensor. An electronics package will be developed to allow the sensor to become "smart" without the use of PC-based software. Also, an attachable version of the sensor will be developed, in which the sensor would be fabricated on metal or ceramic shims for installation into systems that cannot have the sensor deposited directly onto components because of component size or geometry.

The development of sensors to determine simultaneous operating conditions is fundamental in improving system safety and design and development costs. At NASA Glenn Research Center, we have begun testing an integrated sensor design that can measure strain, heat flux, temperature and flow in one smart sensor that is minimally intrusive and survivable in harsh environments.

\section{REFERENCES}

${ }^{1}$ H.A. Will, H. Bhatt. "Status of Thin Film Heat Flux Sensors," Advanced Earth-to-Orbit Propulsion Technology 1994, NASA Marshall Space Flight Center. AL. May 17-19. 1994.

2 J.F. Lei, L.C. Martin. H.A. Will, "Advances in Thin Film Sensor Technologies for Engine Applications." NASA TM-107418. Turbo Expo '97, Orlando, FL. June 2-5, 1997.

${ }^{3}$ J.F. Lei, G.C. Falick \& M.J. Krasowski, "Microfabricated Multifunction StrainTemperature Gauge," US Patent 5,979,243. November 9, 1999.

${ }^{4}$ C.O. Hulse, R.S. Bailey, F.D. Lemkey, "High Temperature Static Strain Gage Alloy Development Program." NASA CR-174833, 1985.

5 J.F. Lei, W.D. Williams, "PdCr Based High Temperature Static Strain Gage," AIAA $2^{\text {nd }}$ International Aerospace Planes Conference, Orlando, FL. October 29-31, 1990.

${ }^{6}$ W.D. Williams, "Strain Sensing Technology for High Temperature Applications," NASA TM4498, AlAA $4^{t_{1}}$ Intemational Aerospace Planes Conference, Orlando, FL, December 1-4, 1992.

${ }^{7}$ S.P. Wnuk, Jr., V.P.Wnuk. "The Development of a $\mathrm{PdCr}$ Integral Weldable Strain Measurement System Based on NASA Lewis PdCr/Pt Strain Sensor for User-Friendly Elevated Temperature Strain Measurements," NASA CR-202316. February 1997.

${ }^{8}$ J.F. Lei, L.C. Greer III, L.G. Oberle, "Evaluation of Pd-Cr Wires for Strain Gage Application," NASA TM-106857. February 1995.

${ }^{9}$ H. Bhatt, M.V. Zeller \& H.A. Will, "Novel ThinFilm Heat Flux Sensors," National Aerospace Planes Conference, Orlando. FL. Dec 1-4. 1992.

${ }^{10}$ C.A. Blaha, "Liftoff Process of Difficult and NonEtchable Material using Photolithography," to be published in NASA Tech Briefs.s

${ }^{11}$ G.C. Kuczynski, "Effect of Elastic Strain on the Electrical Resistance of Metals." Physical Review, Vol. 94, No. 1, 1954, pp. 61-64. 


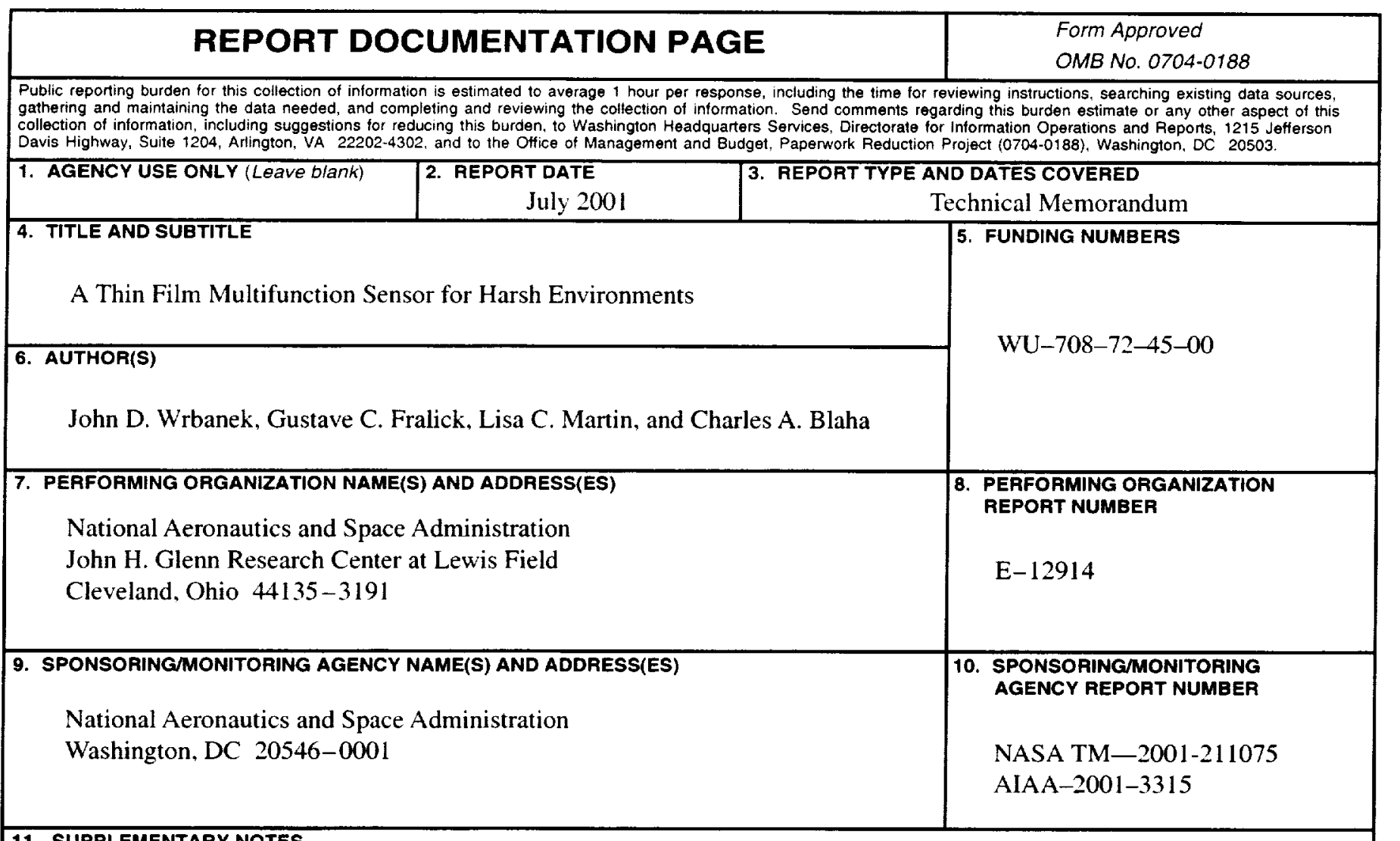

11. SUPPLEMENTARY NOTES

Prepared for the 37th Joint Propulsion Conference and Exhibit cosponsored by the AIAA, ASME, SAE, and ASEE, Salt Lake City, Utah, July 8-11, 2001. John D. Wrbanek, Gustave C. Fralick, and Lisa C. Martin, NASA Glenn Research Center: Charles A. Blaha, Akima Corporation, 22021 Brookpark Road, Cleveland, Ohio 44126. Responsible person, John D. Wrbanek, organization code 5510,216-433-2077.

\begin{tabular}{|l|l|}
\hline 12a. DISTRIBUTION/AVAILABILITY STATEMENT & 12b. DISTRIBUTION CODE
\end{tabular}

Unclassified - Unlimited

Subject Category: $35 \quad$ Distribution: Nonstandard

Available electronically at bttp://gltrs.grc.nasagov/GLTRS

This publication is available from the NASA Center for AeroSpace Information, 301-621-0390.

13. ABSTRACT (Maximum 200 words)

The status of work at NASA Glenn Research Center to develop a minimally intrusive integrated sensor to provide realtime measurement of strain, heat flux and flow in high temperature environments is presented in this paper. The sensor can be beneficial as a single package to characterize multiple stress and strain modes simultaneously on materials and components during engine development and validation. A major technical challenge is to take existing individual gauge designs and modify them into one integrated thin film sensor. Ultimately, the goal is to develop the ability to deposit the sensors directly onto internal engine parts or on a small thin substrate that can be attached to engine components. Several prototype sensors constructed of platinum, platinum-rhodium alloy, and alumina on constant-strain alumina beams have been built and bench-tested. The technical challenges of the design, construction, and testing are discussed. Data from the preliminary testing of the sensor array is presented. The future direction for the sensor development is discussed as well.

\section{SUBJECT TERMS}

Thin film sensor; Strain; Heat flux; Temperature; Instrumentation; Harsh environment

\begin{tabular}{|c|c|c|}
\hline $\begin{array}{c}\text { 17. SECURITY CLASSIFICATION } \\
\text { OF REPORT } \\
\text { Unclassified }\end{array}$ & $\begin{array}{c}\text { 18. SECURITY CLASSIFICATION } \\
\text { OF THIS PAGE } \\
\text { Unclassified }\end{array}$ & $\begin{array}{c}\text { 19. SECURITY CLASSIFICATION } \\
\text { OF ABSTRACT } \\
\text { Unclassified }\end{array}$ \\
\hline
\end{tabular}

NSN 7540-01-280-5500 